\title{
Singing and spirituality in a South African male voice group
}

\author{
Dawn Joseph, Deakin University
}

Roy Page-Shipp, University of Pretoria

Caroline van Niekerk, University of Johannesburg

\begin{abstract}
Since the mid 1970s, a group of twelve business and professional members of a male singing group have continued singing together in Pretoria, South Africa. These singers were interviewed as part of a project on Spirituality and Well-being: Music in the community. From the interview data, two overarching themes emerged, membership benefits and spiritual connections; these are discussed in this research project. Members' views of benefits related mainly to fulfilment of personal, including musical, needs, although all were gratified that their singing provided enjoyment to community audiences and benefits to disadvantaged communities, mainly from ticket sale proceeds. Most saw an association between singing and the spiritual, but only a minority identified a religious connotation, the remainder relating to non-religious factors such as the 'human spirit'. A deep sense of commitment and a love of music impacts positively on social engagement, benefiting and enhancing quality of life for the group members.
\end{abstract}

\section{Keywords}

community

group

singing

social engagement 
spirituality

well-being

\section{Introduction}

Music is enjoyed by all ages across diverse cultures around the world and research shows the essential role that music plays in people's life journey (Coffman 2006; Kruse 2007). In particular, as one ages, music tends to form a fundamental aspect of lifelong learning and is reflected in personal enjoyment and fulfilment (Tsugawa 2009; Kuntz 2012). Music studies undertaken with adults suggest that participants identify improved social connections, enhanced quality of life, benefits to mental well-being and better health (Coffman 2002a, 2002b; Dabback 2005; Rohwer 2005; Rohwer and Coffman 2006; Bowles et al. 2013; Veblen 2013; Weinberg and Joseph 2017).

Cavitt (2005), in a study on community bands, found that adults mainly join ensembles for the love of music as they derive much gratification from playing together. Similarly, people find much fulfilment when singing together as they form a community as singers (Dore et al. 2010). Through song people find a way to express emotions, feelings and thoughts that can enhance meaning in life (Chong 2010). Singing is a vibrant activity that takes place in both formal and informal settings around the globe (Bell 2004; Higgins 2008; Bartleet et al. 2009). Singing in a choir or in a group promotes social, emotional, physical and spiritual health (Bailey and Davidson 2002; Gridley et al. 2011). The notion of music engagement amongst members of a group has 'been found to support group identity, collaborative learning, friendship, [and] social support' (Creech et al. 2014: 17). People singing together provides opportunities for group identity and a sense of connection (Bartleet et al. 2009; Schippers 2010; Gridley et al. 2011; Higgins 2012; 
Veblen 2013). Tsugawa (2009:7) noted in his study of two concert bands that music contributed significantly to the musicians' sense of identity as it formed 'a significant part of their lives'; their rehearsals and concerts exemplify a culture of musical communication between members of the ensembles.

This interaction and engagement is an essential part of the rehearsals of the group in this case study, where members look forward to seeing their friends as a form of social interaction (Coffman 2002a; Jacob et al. 2009). Membership in singing groups offers social affirmation for both the individual and the group (Davidson et al. 2014; Skingley et al. 2015) many people have experienced music offering a social rather than a merely individual identity (Benzon 2001). The members of the group feel connected as they contribute to the social fabric of their community, which is certainly the situation with the group under discussion in this research project, inter alia as they find themselves communicating with their audiences (Pitts 2005).

Some of the benefits of group singing appear to have neuro-chemical origins; participation in music making leads to the secretion of oxytocin (Levitin 2010), 'known to be involved in establishing bonds of trust between people' (Kosfeld et al. 2005). Freeman (2000) goes so far as to describe music as the 'biotechnology of group formation'. Tarr et al. (2014) have also identified an association between the self-other and neuro-hormonal mechanisms in the social bonding arising in music activities.

\section{Well-being}

Several studies have shown how singing is beneficial for well-being (Hays and Minichiello 2005; Chorus America 2009; Clift and Hancox 2010; Menehan 2013a, 2013b; Southcott and Joseph 2013; Specker 2014; Wlodkowski and Ginsberg 2017). 
Though Clift (2012) suggests 'there is some way to go' before any substantial connection between music and well-being can be agreed on, Lehmberg and Fung (2010) found in their study about the benefits of music participation for senior citizens that the longer you engage with music over your lifetime, the greater and more positive the benefits seem to be. In the main, people sing for fun as a leisure activity and this impacts on their quality of life (Huxhold et al. 2013; Lui and Stebbins 2014). Singing acts as a positive mechanism towards social relationships (Pearce et al. 2015). Music has a strong connection to body, soul and mind and has the power to foster an enhanced sense of wellbeing and quality of life (Silverstein and Parker 2002; Joseph 2014; White 2016).

\section{Spirituality}

Music is also associated with the multidimensional experience described as 'spirituality', which arises in many contexts that include both the religious and the secular where music is made or heard (Cobussen 2008). Attempts to describe the phenomenon include that by Veselinović-Hofman (2009: 116) whose description of spirituality is an 'open space' that 'lies in between the human and the divine'.

Finding a clear definition that would enable spirituality to be explored via a more scientific approach was addressed by Sir Alister Hardy, who in the late 1960s brought his experience as a zoologist to bear on the search for a 'common core' in the world's religions. By defining very clearly and specifically what he was looking for, Hardy created a question that many people could answer with a simple Yes or No, without having to deal with abstract notions. The question was 'Have you ever had a spiritual or religious experience or felt a presence or power, whether you call it God or not, that is different from, or more than, your everyday self' (Rankin 2008: 234). This formulation, 
in various derivatives, has been sufficiently accessible for thousands of subjects to answer in the affirmative (Badham 2012). Indeed, Badham argues that 'once one moved away from abstract concepts and asked about personal experience' it became possible to extend the study across religions. Providing further clarity, the confusion between religion and spirituality has been gradually replaced by the recognition that spirituality can be related to religion or can be 'religionless' (Boyce-Tillman 2016), confirming that this interplay is often connected with an individual's beliefs and values rather than, or in addition to, religious doctrine. As a basis for research this approach seems more likely to uncover human experience than a belief that spirituality may be characterized by 'mystical, transpersonal, transcendent and numinous' experiences (MacDonald 2000).

Returning to the specific role of music, Anne Lipe (2002: 210) argues that, throughout history, music has played a significant role 'in religion and spiritual life [...] across cultures' and 'can serve as a sacramental vessel [...] to nourish our [one's] spiritual life'. June Boyce-Tillman (2012: 33-34) uses music (voice) in the venue of 'the cathedral as a resonant mediative space' merging diversity amongst 'community choirs, school choirs from church and state schools, the university, the cathedral choristers, a rabbi, a Jewish cantor, a Muslim imam, a singer in the Hindu/Sikh tradition, a Bahá'i singer, and Buddhist chanters' in order to explore and promote the experience of space which resonates with spirituality. Music (singing) in this space can then be considered 'a medium of transcendence and a language of spirituality' (Foley 2015: 638).

\section{Context: South Africa}

South Africa is widely regarded as the powerhouse of Africa (Joseph et al. 2014), after Asia the second largest continent in the world, where 'population is aging simultaneously with its unprecedented growth of the youth population and its related challenges' 
(Nabalamba and Chikoko 2011: 2). In South Africa, the expected growth rate of older people will increase by 10.5 per cent by 2025 (Joubert and Bradshaw 2006). This research project situates itself in the administrative capital Pretoria, part of the Tshwane metro, with the third largest population in the province of Gauteng. 'Whites make up a larger percentage of the population in Tshwane than in any other major metropolitan area in the country' (SAPA 2013). Within the White group, English speakers are in a distinct minority, the others being mostly Afrikaans speaking.

Though South Africa boasts a rich history of music and culture across all races, this research project focuses on only one singing group in the metropolitan area of Pretoria where group members are aged from 60 upwards. This group is an example of older white men and one white female who have continued with their project of making and sharing music in their local community for the unusually long duration of over 40 years, that period of time immortalized in the school anthem for Harrow, interestingly also adopted by the Pretoria Boys' High School, with which a number of members of this singing group have associations. The song 'Forty Years On' can be sung in unison or two part singing with the melody in the upper part (Farmer and Bowen 1930) and is usually sung whenever Old Harrovians gather, enduring far beyond their schooldays. 'Forty Years On' has become known as 'The Harrow Song' (Harrow School 2017). Maclure (1985: 117) found the song resonates with feelings of the 'good old days', 'nostalgia and sentimentality'. Singing together and songs such as 'Forty Years On' provide ageing people with the opportunity to continue singing. 


\section{Purpose of the research project}

The purpose of the research project was to investigate music, well-being and spirituality through community music making in various organizations in the Australian state of Victoria. In 2015 further approval was gained from Deakin University’s Human Research Ethics Committee (DUHREC) to include South Africa and two co-authors for this research project. Some of the aims of the project were to investigate and identify:

- Why do people come together to share music making and practice?

- What are the benefits of community music making?

- Does music making connect to spirituality?

- Can music making and sharing contribute to one's well-being?

Author 1, who is formerly from Johannesburg, visited South Africa in 2015 and communicated through Skype, e-mail and telephone with Authors 2 and 3, regarding the data collection process. For this research project, interview data is drawn on to discuss some of the key findings.

\section{Authors}

All three of the authors have strong links to music teaching, learning and performing in their respective settings. Authors 1 and 2 are tertiary music academics and Author 3 is a retired science research manager and a long-standing singing member of the group discussed here. In 2013, Author 1 gained ethical approval through DUHREC and started the long-term project Spirituality and Well-being: Music in the community, in Melbourne, Australia. DUHREC manages the research integrity of the project by approving all letters, questionnaires and semi-structured interview questions sent out to potential participants. All participants can communicate directly with the Manager of the 
Research Integrity Unit at the university if they have any concerns about any aspect of the project, the way it is being conducted or ask any questions about their rights as research participants.

\section{Background to the group in Pretoria}

In the 1970s a small band of singers in Pretoria formed a male voice singing group including one member of the current group and the pianist accompanist, who was a music teacher at the time, and the only person in the group who could be described as more than a purely amateur musician. Only these two remain members after more than 40 years. The group now comprises eleven members (basses and tenors), mostly former business and professional men, suggesting that their careers and working lives would have offered them significant personal satisfaction and thus be an aspect now missed in retirement, and a need requiring fulfilment which they appear to find in the activities of this group (de Jong Gierveld et al. 2016). The accompanist continues in her role. The ages of members range from 60s to 80s and they include a judge, a professor and CEOs of a companies. They sing a wide range of repertoire including madrigals, Negro spirituals, sacred items, traditional songs (Scottish, Irish, Welsh, English and Afrikaans), love songs, lullabies, drinking songs, humorous songs, songs from musicals and thus far one African (Xhosa) song. The emphasis reflects the taste of many White, English-speaking South Africans, with a slow move towards adopting some indigenous music. The group is 'English', as White South Africans whose home language is English are usually described and who were in a significant minority among Whites in Pretoria during the apartheid years.

The group relies heavily on the accompanist for musical coaching and guidance; only three singers claim to sight-read, although most find music notation helpful. The accompanist makes constructive critical comments on the quality, accuracy and style of 
the music. One of the members is designated to manage the group in relation to providing copies, keeping records of performances and leading the choice of items in rehearsal. The group rehearses once a week for approximately 90 minutes and gives two public concerts a year where proceeds go to a deserving cause, thereby responding to the many financial needs in South Africa (Prilletensky and Prilletensky 2006). In addition, the group performs several times during the course of the year at retirement villages, sometimes also being called upon as 'warm-ups' for public concerts.

Although membership of the group is by invitation, usually emanating from the founder member, all members are involved in the assessment of potential newcomers. Apart from the ability to learn and hold a singing part, an essential and fairly objective characteristic, all are assessed in terms of the, more subjective, expected 'willingness and ability to fit in'. This relates mainly to social compatibility - one member referred to the group as 'like-minded individuals' - but also to a lifestyle that provides for regular rehearsing and performing. Eight of the eleven members were recruited after participation in one or more annual operetta productions of an amateur group in Pretoria, as this has proved to be a reliable screen.

\section{Methodology}

For this research project, the authors employ case study methodology (Yin 2003) to explore the lived experience of our interviewees. The case study presents a 'localized boundary of space and time', where trust is important when collecting interview data as they form the case record to tell the story (Bassey 2003:117). The authors take into account the personal element of making meaning (Crabtree and Miller 1999; Yin 2003) from the participants where Author 3, a singing member of the group, is able to 
collaborate and gain an insider's perspective among the participants. This was also the case with Author 2, who interviewed the accompanist with whom she is very familiar. Author 1 prepared the interview questions, which were used to guide the interview process. These questions were short and clear, avoiding any form of ambiguity to achieve reliability and validity (Csikszentmihalyi and Larson 2014). Interviewees were all given the Deakin University Plain Language Statement to read and were invited to participate in the project. Author 3 further explained the process, encouraging participation to gain a higher response rate (Baldwin and Beauchamp 2014). By agreeing to the interviews and vetting the transcription summaries thereof the participants consented to take part in the research study.

All eleven singing members and the accompanist were interviewed. Sixteen questions were asked: two closed questions focused on age and gender and fourteen were openended. The closed questions characterized the group as comprising only 'mature' males. Some of the open-ended questions included: What made you join the group? What do you benefit from attending this group? An open-ended question was used in thus study to identify where subjects position their 'spirituality' experiences.-According to Cohen et al. (2000: 255), the use of open-ended questions is 'a very attractive device for smaller scale research $[\ldots]$ that invite an honest personal comment'.

The accompanist was asked the same questions; as a foundation member of the group her information and insights are particularly valuable (Gill et al. 2008). All participants had 'the opportunity to discuss and clarify the interpretation, and contribute new or additional perspectives on the issue under study' (Baxter and Jack 2008: 556).

We used Interpretative Phenomenological Analysis (IPA) to analyse and code the data. IPA provided the understanding of how the group make sense of their experiences and 
the meanings they attach to them (Smith 2011). It also gave us the chance to explore the expressed views of the individual participants, with sensitivity to the 'setting, the sociocultural and linguistic context of the research' (Yardley 2017). Katherine Finlay and James Elander (2016: 665) make the point that when using IPA 'the researcher's own views may impact upon the representations of interviewees', thus involving a process of interpretation by the researcher(s) (Smith 2005; Clarke 2009). In this study we have kept to the phenomenon and to the setting which we explored (Padgett 2017). As researchers we had to listen, understand and trust each participant's voice when interpreting the data. Having read and analysed the interview data, initially making notes and grouping them in tables (Smith and Osborn 2003, Finlay and Elander 2016), we had a three-way discussion and then re-read the tables, focusing on pertinent aspects of the data and grouping them into two overarching themes. As examples of this process and output we very readily identified the dichotomous nature of the responses relating to spirituality, and were able to identify a common perception of a very relaxing environment - albeit expressed in different words - that had been beneficial, not only in stressful working lives, but continued as a benefit in retirement (see Findings and Discussion below). The use of direct quotations highlights the theme under discussion (Larkin et al. 2006; Smith et al. 2009; Finlay and Elander 2016).

\section{Findings and discussion}

The two overarching themes emerging from the interview data are: benefits of membership and spirituality connections to music making. 


\section{Benefits of membership}

Over the years members have accepted invitations to join the group for a number of reasons, but the most common was because of their love of singing. They remain in the group, as Buck said, because 'it continues to fulfil my need for active music participation'. Mac added 'it all still works for me, the music learning and performing new pieces, the fellowship'. The desires for both 'intellectual stimulation and relaxation' were important factors why members remained in the ensemble (Don and Buck). Joan, the accompanist, who plays a key role in the group, pointed out why she has been with them for four decades already: it is 'because I still enjoy accompanying, and my musical activities give my life focus'.

Many members have been part of this group from a time when they would not be considered 'older people'. However, these points are all applicable to and confirmed by them, each strongly expressing a deep sense of commitment to the group and a love of music in relation to making music together (singing or accompanying). Individually and collectively members have remained in the group for a variety of reasons. Words such as 'enjoyment', 'fun', 'fellowship', 'camaraderie' and the phrase 'singing with like-minded people' occurred twelve times in responses to the question 'why did you join the group?' Though this is not uncommon in choirs or singing groups, the founder member (Bill) said:

I have seen the benefits of group singing in many ways $[\ldots]$ and believe that I have introduced thousands to the joy of community singing. This counters the experience of so many people who have been persuaded by an event in early 
life that they 'can't sing' - the scars being so deep and painful that they can recall the occasion/interaction in significant detail.

This experience was affirmed by several members whose acceptance in the group had restored their confidence in a singing ability suppressed by bad experiences in their youth. Members 'love singing'; Schalk found the group 'incredibly relaxing, focusing on something pleasant'. The environment and ambience is 'relatively un-taxing compared with other commitments' (Eddie). This is a space for all members to thrive, a place where members feel 'energised by the other members' (Bill), and this makes it more sustainable as 'a clean sport' as Schalk remarked. The rehearsals and membership Mick noted as 'undemanding of each other'. Trevor added, 'we seem to secrete a "happy" hormone while singing. I enjoy every occasion and often arrive home afterwards whistling'. The level of commitment and wanting to sing new and different repertoire 'provides a challenge to continue to sing at an acceptable level' (Bill).

In addition, members commented on the benefits of singing that impacted on their wellbeing. Chad, a recent recruit, reported 'my enjoyment of life has increased and I want never to miss a rehearsal, even though some may be chaotic. My narrow view of life has "exploded". In this sense, there is more to just learning the notes and singing for this person: membership opens a new world of repertoire, performances and friendship. What the group gains is more than just singing: as Buck stated, 'it's a good mood improver and I would miss this sustenance if it were absent'. Attendance played a major role in rehearsals as it impacts on well-being. Don confirmed 'huge emotional attachment' and noted 'I sing when I am happy, less often when I am not; but singing tends to lift the mood'. Though this study did not specifically explore the clinical implications of singing, Schalk confirmed that singing in the group 'takes my mind off recent chemotherapy'. 
Joan pointed out 'I don't know if my health is better or not, but it keeps me active, participating in community life'. For many members being part of an active vibrant community contributes to their sense of happiness and offers a sense of fulfilment. This was confirmed by Mac who said, 'it would grieve me to lose it, it definitely contributes to my overall sense of well-being'.

The benefits of membership extend beyond the group to the wider community in relation to regular performances given. Some of these performances are free and others are charged for, but then the proceeds go to non-profit organizations and good causes. This point the group feel is particularly important in a country as disparate as South Africa, where there are so many needs and especially in relation to people who are 'have nots' in comparison with the twelve individuals under discussion.

The group members do not organize concerts or sell tickets themselves; rather all members are gratified that the funds raised go to the deserving cause for which they are intended. Bill said when they perform at 'retirement villages or in concerts, we provide a form of public benefit'. This they recognize as a welcome community contribution. According to Mac the group has "many fans (mainly ladies) who report that they "love" our singing. Our concert proceeds always go to charity and we are always sold out'. Joan said 'we make money for charity with our performances. I feel I make a contribution; there are not so many people prepared to do this for nothing'. In her role as accompanist Joan also finds involvement in the group twofold: 'it can give pleasure to others in the community as well as to the group and that gives satisfaction and enjoyment'. Jack, Chad and Don concurred. The notion of community engagement is important to the group Trevor talks of 'many people sharing our enjoyment of singing and we promote this experience in our audiences (we encourage occasional sing-alongs)'. 


\section{Spiritual connections to music making}

Having asked for a clear definition of spirituality and been invited to provide their own, the respondents provided answers that can be grouped as:

Yes

2 (Religious, but in worship, not in the group)

7 (Non-religious, in the group)

1 (All types of music)

No

2

The notion of spirituality meant different things to individuals in the group. A common initial response (from nine of the eleven respondents) to the question 'Does music making connect to spirituality?' was 'It depends what you mean by spirituality'. The question had been deliberately broadly stated to allow for the possibility that some members may not have deeply considered whether music has such a connection. As they are all highly educated and articulate, and were also being interviewed, not asked to complete a questionnaire, this reaction could be followed through. Indeed, after an invitation to make their own interpretation of the term, insightful responses emerged. The distinction between religious and religionless spirituality was generally recognized.

The accompanist, who for decades has been instrumental in the group (pun not intended, as the only person playing an instrument in comparison with the rest as singers), felt that spirituality has a connection to any kind of music making. She believes 'music occupies your body, your brain and contributes to your spirit'. This connection affects one's 
energy field and sense of spirituality. In contrast, Jack admitted, 'I do not profess to fully understand the workings of the mind when enjoying music'. For him, the aesthetic experience seemed more the focus than the spiritual connections. The core of what spirituality meant was deemed debatable as Schalk found it 'hard to explain' whilst Bill professed that he was 'aware of a good "vibe"". This 'vibe' may have been a feeling that uplifted his inner spirit and made him feel good per se. Schalk agreed that the experience of singing does not evoke a religious spirituality but rather, 'I sense something special; a connection to something special, bigger or beyond ourselves'. Such feelings created a profound perception of well-being for the majority of the members: as Chad remarked, his sense of spirituality was not religious as such; rather, 'I do derive a lift from participation. Perhaps that is spiritual'.

The connection to participation and sharing in a secular sense also offers members a possible sense of spiritual connection. Trevor upholds 'I am not a churchgoer but believe that the human spirit is real and this is important to me. This spirit is "deeper" than the mind and can be uplifted by music'. He further claims it is that sense of inner spirit that 'appears to be characteristic of all musicians'. Buck confirmed, 'music is very spiritual'; for him, music has connections to being a powerful agent 'in transforming one's mood'. Mick pointed out: 'good music can be moving'. Three other members (Mac, Simon and Jack) mentioned that the positive feelings they experienced could have neurochemical or hormonal origins; 'some of it must be oxytocin!' as Mac expressed it.

Two members related their sense of a spiritual connection with singing specifically to experiences from their early youth in church choirs, i.e. to religious spirituality. Don said, 'having been a boy chorister and sung in choirs all my life I associate singing with worship'. The idea that music connects to religious settings or singing about God is not a 
new phenomenon as this practice is referred to in the earliest writings on Judaism, for example. Eddie echoes this by confirming 'there is a deep spiritual connection to songs sung in Church. The word of God set to music has meaning and fosters a sense of connection to the individual and to the collective membership of the church'. However, he does not see any spiritual connection arising from the group's repertoire - even Negro spirituals. Don also claimed that music and spirituality have a connection because scripture can be taught, 'from singing psalms and other sacred music'. This is in contrast to Mac, 'a committed Christian', who has sung in many church choirs and feels aware of God's Holy Spirit, but feels that 'many pieces are touching and uplifting and one responds with one's whole being'; yet, he could not 'identify a special spiritual aspect' in any religious sense, to music. In a similar way Simon was forthright in saying 'I don't believe that there is any connection between one's experience of singing and the divine and, therefore, do not believe singing can provide a spiritual experience'.

The reported spiritual connections relating to music in religious practices, or alternatively connections to aspects of 'body, mind and spirit' affirm that the term spiritual experience 'signifies something special but not necessarily with a religious connection'. Rather it would seem the understanding locates itself in 'what we think and what we believe' (Pretorius 2008: 148). Freinkel (2015:159) suggests that 'performing singers sing in relationship and the individuals in the audience participate and form loci for the cocreative emergence of spiritual knowing that sometimes takes place'. That may be true for this group, but it is not formally acknowledged and this thought can be constructively introduced into the group's activity.

\section{Conclusions and recommendations for further research}

Music creates a sense of belonging for both young and old (Eidevall and Leufstadius 
2014) and group singing specifically fosters a sense of personal growth and well-being where participants feel valued as a group (Zanini and Leao 2006). Membership of the group in our research project is driven primarily by the fulfilment of members' personal and musical needs as they share social learning and social interaction (Mao et al. 2016).

Joan is unique in her role as the group's only accompanist since it started in the 1970s; she plays an indispensable role in motivating and teaching the members, which positively contributes to their sense of well-being. Members feel validated, and their active engagement through singing impacts on their overall well-being (Hays and Minichiello 2005; Specker 2014; Wlodkowski and Ginsberg 2017). The group remains enthused to gather weekly for rehearsals with Joan and each other: they interact socially with likeminded people and this further strengthens the unity within the group and adds to their quality of life (Huxhold et al. 2013). In addition, the connection of singing with each other as a community contributes to life satisfaction (Silverstein and Parker 2002; Weinberg and Joseph 2017). It would seem that social engagement by way of 'social togetherness' strengthens the camaraderie and friendship 'teamwork with a clear vision of bringing to oneself and others'. Participating in 'regular, harmonious and fun interactions with uncompetitive other music lovers' in a singing group boosts quality of life and may reduce financial toll on health and social services. The latter aspect of the research project requires further investigating with many more groups.

The group in itself has had a very close social and learning connection for well over forty years and they bring much joy to others by singing to, for and with them. The findings from Lee et al. (2016) of motivating factors or themes for older people's participation in community singing resonated with our research project:

- The importance of singing in my life 
- Enormous pleasure of singing with little pressure

- Challenge and achievement

- Spiritual and uplifting emotions

- Strength in overcoming my age, disease and hardship

- Good leadership

- Fellowship with others

- Purpose and meaning of group singing.

Appreciative audiences also contribute to the singers' feelings of satisfaction and wellbeing (Packer and Ballantyne 2011) and so does the social interaction of performers and audiences (Pitts 2005). It would seem the concerts provide a sense of 'entertainment to many' especially those that regularly support the performances. The 'rush from an enthusiastic audience response' it would seem is good for listener and performer as a way to positively enhance well-being across all ages. What the members experience as their heightened well-being as a result of their participation is clear from their own words, quoted above but here listed alphabetically: active, cameraderie, clean sport, energized, enjoyment, fellowship, fun, intellectual stimulation, mood improver, participating, relaxation, and untaxing. The positive relationships created through years of singing attest to members' commitment as a community of singers, positively adding to their sense of well-being (Skingley et al. 2015). For some members, retired from their business and professional lives, the weekly rehearsals may help reduce current social isolation where many would previously have been actively involved in their workplaces (de Jong Gierveld et al. 2016). Singing in a group may offer its membership a sense of gratification especially when preparing for a concert as 'it gives the group something positive to work towards'. Also, the group's involvement with fundraising is an example 
of how older people in a country like South Africa still have the capacity to contribute to 'responsiveness to common good' (Prilletensky and Prilletensky 2006: 235).

The responses to the question on a 'spiritual connection to music' revealed a general unprompted awareness of the distinction between religious and non-religious spirituality. The group varied in their understanding of music and spirituality where the notion of spirituality is an open space 'somewhere in-between the human and the divine' (Veselinović-Hofman 2009: 116, original emphasis); a space where body, mind and soul perhaps connect to something that is beyond words to explain - something ethereal. For some members, the association of music to worship and to the word of God was strong as they connected singing with worship and for others music and spirituality had secular and celestial connections. The extent of the association to religious or spiritual qualities in music requires further investigation, bearing in mind Westermeyer's 2013 article that focuses on the words of God as central to Christian spirituality. In exploring this issue, one would need a more specifically formulated set of questions that enable members - or another group of respondents - to locate their sense of 'spirituality' and explore the matter more deeply themselves. In the group such discussion may act a springboard to more satisfying experiences.

This small study of amateur singers investigates a seriously underreported aspect of singing in South Africa - a country where especially choral participation is extremely popular, and yet there is a paucity of research amongst older singers. This research project is unique in that the group remains White English-speaking in a predominantly Afrikaans-speaking area (Pretoria). The research project adds to the body of knowledge on the myriad physical, social and health benefits of community singing and these benefits are underscored by the evidence that the members still sing together 'Forty Years 
On', demonstrating singular commitment and not mere social engagement. Music for them 'creates a sense of belonging and community' (Dore et al. 2010: 10) and certainly the longevity of the group confirms Lehmberg and Fung's 2010 finding that length of senior citizens' engagement with music results in 'greater and more positive' benefits.

The search is also underway to identify and then interview other amateur singing groups of similar long-standing, so as to ascertain whether their views on the benefits of their groups' activities are similar to those of the group under discussion in this research project. Consideration can be given too to a further study or studies entailing observation (in addition to interviews) of amateur musicians' interaction with each other as they rehearse and perform music. This may provide the authors - and others - with a deeper understanding of how music intersects with well-being and spirituality. The wider sampling that this will achieve may reveal more generalized insights. Such groups need not be based in South Africa, although if the groups are not functioning in highly disparate societies the aspect of community (and especially financial) contribution might not be present to the same extent. By the same token, other musical groups (e.g. chamber music players) who do not sing might not demonstrate a reflection of the significance of words found in songs.

\section{References}

Badham, Paul (2012), 'Researching religious experience from a comparative perspective - the Alister Hardy Global Project', Interreligious Insight, 10:2, pp. 18-28. 
Bailey, Betty. A. and Davidson, Jane W. (2002), 'Adaptive characteristics of group singing: Perceptions from members of a choir for homeless men', Musicae Scientiae, 2:2, pp. 221-56.

Baldwin, Lara and Beauchamp, Gary (2014), 'A study of teacher confidence in teaching music within the context of the introduction of the Foundation Phase (3-7 years) statutory Education Programme in Wales', British Journal of Music Education, 31:2, pp. 195-208.

Bartleet, Brydie-Lee, Dunbar-Hall, Peter, Letts, Richard and Schippers, Huib (2009), 'Sound links community music in Australia', Queensland Conservatorium Research Centre Griffith University, Brisbane, http://www.griffith.edu.au/_data/assets/pdf_file/0009/159282/Sound-Links-BookWeb-Resolution.pdf. Accessed 12 February 2015

Bassey, Michael (2003), 'Case study research', in Joanna Swann and John Pratt (eds), Educational Research in Practice: Making Sense of Methodology, London: Continuum, pp. 111-24.

Baxter, Pamela and Jack, Susan (2008), 'Qualitative case study methodology: Study design and implementation for novice researchers', The Qualitative Report, 13:4, pp. 544-59.

Bell, Cindy L. (2004), 'Update on community choirs and singing in the United States', 
International Journal of Research in Choral Singing, 2:1, pp. 39-51.

Benzon, William. L. (2001), Beethoven's Anvil: Music in Mind and Culture, Oxford: Oxford University Press.

Bowles, Chelcy, Dabback, Will and Myers, David (2013), 'Music learning as a lifespan endeavor', in Kari K. Veblen, Stephen J. Messenger, Marissa Silverman and David J. Elliott (eds), Community Music Today, Landham, MD: Rowman and Littlefield Publishers, pp. 133-50.

Boyce-Tillman, June (2012), 'Music and the dignity of difference', Philosophy of Music Education Review, 20:1, pp. 25-44. (2016), Experiencing Music - Restoring the Spiritual; Music as Well-Being, Bern: Peter Long AG.

Cavitt, Mary E. (2005), 'Factors influencing participation in community bands', Journal of Band Research, 41:1, pp. 42-59.

Chong, Hyun J. (2010), 'Do we all enjoy singing? A content analysis of non-vocalists' attitudes toward singing', The Arts in Psychotherapy, 37: 2, pp. 120-24.

Chorus America (2009), 'New study finds the positive benefits of choral singing are stronger than ever', Voice of Chorus America, 32:4, pp. 38-44. 
Clarke, Channine (2009), 'An introduction to interpretative phenomenological analysis:

A useful approach for occupational therapy research', British Journal of Occupational Therapy, 72:1, pp. 37-39.

Clift, Stephen (2012), 'Singing, wellbeing, and health', in Raymond A. R. MacDonald, Gunter Kreutz and Laura Mitchell (eds), Music, Health, and Wellbeing, Oxford: Oxford University Press, pp. 113-24.

Clift, Stephen M. and Hancox, Grenville (2010), 'The significance of choral singing for sustaining psychological wellbeing: Findings from a survey of choristers in England, Australia and Germany', Music Performance Research, 3:1, pp. 79-96.

Cobussen, Marcel (2008), Thresholds: Rethinking Spirituality Through Music, Burlington, VA: Ashgate.

Coffman, Don D. (2002a), 'Banding together: New horizons in lifelong music making', Journal of Aging \& Identity, 7:2, pp. 133-43.

(2002b), 'Music and quality of life in older adults', Psychomusicology, 18:1-2, pp. $76-88$. (2006), 'Voices of experience: Interviews of adult community band members in Launceston, Tasmania, Australia', International Journal of Community Music, 23:1 
(in Selected Papers and Abstracts from the Music and Lifelong Learning

Symposium),

http://www.intellectbooks.co.uk/MediaManager/Archive/IJCM/Volume\%20D/07\%2 0Coffman.pdf Google Scholar. Accessed 12 November 2015

Cohen, Louis, Manion, Lawrence and Morrison, Keith (2000), Research Methods in Education, London: Routledge Falmer.

Crabtree, Benjamin F. and Miller, William L. (eds) (1999), Doing Qualitative Research, 2nd ed., Thousand Oaks, CA: Sage.

Creech, Andrea, Hallam, Susan, Varvarigou, Maria and McQueen, Hilary (2014), Active Ageing with Music, London: Institute of Education Press.

Csikszentmihalyi, Mihaly and Larson, Reed (2014), 'Validity and reliability of the experience-sampling method', in Mihaly Csikszentmihalyi (eds), Flow and the Foundations of Positive Psychology, the Netherlands: Springer, pp. 35-54.

Dabback, Will M. (2005), 'Examining the gap between theory and emerging practice in the instrumental music education of older adults', International Journal of Community Music, 2:1, pp. 1-16. 
Davidson, Jane W., McNamara, Beverley A., Rosenwax, Lorna, Lange, Andrea, Jenkins, Sue C. and Lewin, Gill F. (2014), 'Evaluating the potential of group singing to enhance the well-being of older people', Australasian Journal on Ageing, 33:2, pp. 99-104.

Dore, Coral, Gillett, Susan and Pascal, Jan (2010), 'Community singing and social work: A new partnership', UNESCO Observatory for Multi-Disciplinary Research in the Arts, 2:1, pp. 1-22.

Eidevall, Kristina and Leufstadius, Christel (2014), 'Perceived meaningfulness of music and participation in a music group among young adults with physical disabilities', Journal of Occupational Science, 21:2, pp. 130-42.

Farmer, John and Bowen, Edward E. (1930), Forty Years On: (The Famous Harrow School Song): For Unison or Two Part Singing, Melody in Upper Notes, Melbourne: Allan \& Co.

Finlay, Katherine A. and Elander, James (2016), 'Reflecting the transition from pain management services to chronic pain support group attendance: An interpretative phenomenological analysis', British Journal of Health Psychology, 21:3, pp. 660-76.

Foley, Edward (2015), 'Music and spirituality - introduction', Religions, 6:2, pp. 638-41. 
Freeman, Walter J. (2000), 'A neurobiological role of music in social bonding', in Nils Wallin, Bjorn Merkur and Steven Brown (eds), The Origins of Music, Cambridge, MA: MIT Press, pp. 411-24.

Freinkel, Paul D. (2015), 'Singing and participatory spirituality', International Journal of Transpersonal Studies, 34:1\&2, pp. 152-66.

Gill, Paul, Stewart, Kate, Treasure, Elizabeth and Chadwick, Barbara (2008), 'Methods of data collection in qualitative research: interviews and focus groups', British Dental Journal, 204:1, pp. 291-95.

Gridley, Heather, Astbury, Jill, Sharples, Jenny and Aguirre, Carolina (2011), Benefits of group singing for community mental health and wellbeing, Victorian Health Promotion Foundation (VicHealth), Carlton, Australia.

Harrow School (2017), 'Harrow Songs', http://www.harrowschool.org.uk/songs. Accessed 2 May 2017.

Hays, Terence and Minichiello, Victor (2005), 'The contribution of music to quality of life in older people: An Australian qualitative study', Ageing \& Society, 25, pp. 261-78.

Higgins, Lee (2008), 'Growth, pathways and groundwork: Community music in the United Kingdom’, International Journal of Community Music, 1:1, pp. 23-37. 
(2012), Community Music in Theory and in Practice, New York: Oxford University Press.

Huxhold, Oliver, Miche, Martina and Schüz, Benjamin (2013), 'Benefits of having friends in older ages: Differential effects of informal social activities on well-being in middle-aged and older adults', Journals of Gerontology, Series B: Psychological Sciences and Social Sciences, 69:3, pp. 366-75.

Jacob, Cynthia, Guptill, Christine and Sumsion, Thelma (2009), 'Motivation for continuing involvement in a leisure-based choir: The lived experiences of university choir members', Journal of Occupational Science, 16:3, pp. 187-93.

Jong Gierveld, Jenny de, Tilburg, Theo van and Dykstra, Pearl (2016), 'Loneliness and social isolation', in Anita Vangelisti and Daniel Perlman (eds), The Cambridge Handbook of Personal Relationships, second edition, Cambridge: Cambridge University Press, pp. 1-30, https://research.vu.nl/ws/portalfiles/portal/2173239. Accessed 19 January 2017

Joseph, Dawn (2014), 'Spirituality, music, and wellbeing: Sharing insights from an Australian setting', International Journal of Health, Wellness and Society, 4:2, pp. $1-14$.

Joseph, Nazeer, Erasmus, Wikus and Marnewick, Carl (2014), 'The idle state of information and communication technology project management', Journal of 
African Business, 15:3,

http://www.tandfonline.com/doi/abs/10.1080/15228916.2014.956641\#.VcCRHIvtU 8F. Accessed 20 September 2017

Joubert, Jané and Bradshaw, Debbie (2006), 'Burden of disease: Growing numbers of older persons in South Africa', http://www.sahealthinfo.org/bod/older.htm. Accessed 8 June 2015.

Kosfeld, Michael, Heinrichs, Markus, Zak, Paul, Fischbacher, Urs and Fehr, Ernst (2005), 'Oxytocin increases trust in humans', Nature, 435:7042, pp. 673-76.

Kruse, Nathan B. (2007), 'Andragogy and music: Canadian and American models of music learning among adults', unpublished doctoral dissertation, East Lansing, MI: Michigan State University.

Kuntz, Tammy L. (2012), 'Self-reported personal traits of adult amateur musicians', unpublished doctoral dissertation, Cleveland: Case Western Reserve University.

Larkin, Michael, Watts, Simon and Clifton, Elizabeth (2006), 'Giving voice and making sense in interpretative phenomenological analysis', Qualitative Research in Psychology, 3:1, pp. 102-20. 
Lee, Juyoung, Davidson, Jane W. and Krause, Amanda E. (2016), 'Older people’s motivations for participating in community singing in Australia', International Journal of Community Music, 9:2, pp. 191-206.

Lehmberg, Lisa J. and Fung, C. Victor (2010), 'Benefits of music participation for senior citizens: A review of the literature', Music Education Research International, 4, pp. $19-30$.

Levitin, Daniel (2010), The World in Six Songs, London: Aurum Press.

Lipe, Anne W. (2002), 'Beyond therapy: Music, spirituality, and health in human experience: A review of literature', Journal of Music Therapy, 39:3, pp. 209-40.

Lowis, Michael J. (2010), 'Emotional responses to music listening: A review of some previous research and an original, five-phase study', Journal of Applied Arts and Health, 1:1, pp. 81-92.

Lui, Huimei and Stebbins, Robert A. (2014), 'Concerted singing: Leisure fulfillment in a university faculty chorus', Leisure Studies, 33:5, pp. 533-45.

MacDonald, Douglas A. (2000), 'Spirituality: Description, measurement, and relation to the Five Factor Model of personality', Journal of Personality, 68:1, pp. 153-97. 
Maclure, Stuart (1985) 'Forty Years On’, British Journal of Educational Studies, 33:2, pp. 117-34.

Mao, Mao, Blackwell, Alan F., Lukate, Johanna M. and Good, David A. (2016),

'Supporting retirement socially and musically by technology: An ethnographic study of local community musicians', Proceedings of the 2016 CHI Conference Extended Abstracts on Human Factors in Computing Systems, New York, ACM, pp. 2886-92.

Menehan, Kelsey (2013a), 'Singing and psychological well-being', https://www.chorusamerica.org/singers/singing-and-psychological-well-being. Accessed 13 September 2013.

(2013b), 'Singing and healthy aging', https://www.chorusamerica.org/singers/singing-and-healthy-aging. Accessed 13 September 2013.

Nabalamba, Alice and Chikoko, Mulle (2011), 'Aging population challenges in Africa', AfDB Cjeif Economist Complex, 1:1, pp. 1-14, http://www.afdb.org/fileadmin/uploads/afdb/Documents/Publications/Aging\%20Po pulation\%20Challenges\%20in\%20Africa-distribution.pdf. Accessed 8 June 2015.

Packer, Jan and Ballantyne, Julie (2011), 'The impact of music festival attendance on young people's psychological and social well-being', Psychology of Music, 39:2, pp. 164-81. 
Padgett, Deborah (2017), Qualitative Methods in Social Work Research, New York: Sage.

Pearce, Eilunid, Launay, Jacques and Dunbar, Robin I. M. (2015), 'The ice-breaker effect: Singing mediates fast social bonding', Royal Society Open Science, 2:10, http://rsos.royalsocietypublishing.org/content/royopensci/2/10/150221.full.pdf. Accessed 20 October 2016

Pitts, Stephanie E. (2005), 'What makes an audience? Investigating the roles and experiences of listeners at a chamber music festival', Music \& Letters, 86:2, pp. $257-69$.

Pretorius, Stephan P. (2008), 'Understanding spiritual experience in Christian spirituality', in Pieter. G R. De Villiers, Celia E T. Kourie and Christo Lombaard (eds.), The spirit that empowers: Perspectives on spirituality (Acta Theologica Supplementum 11), pp. 147-165, University of the Free State Press, Bloemfontein.

Prilletensky, Isaac and Prilletensky, Olga (2006), Promoting Well-Being: Linking Personal, Organizational and Community Change, New Jersey: Wiley \& Sons. 
Rankin, Marianne (2008), An Introduction To Religious And Spiritual Experience, London: Continuum International.

Rohwer, Debbie (2005), 'A case study of adult beginning instrumental practice', Contributions to Music Education, 32:1, pp. 45-58.

Rohwer, Debbie and Coffman, Don D. (2006), 'Relationships between wind band membership, activity level, spirituality and quality of life in older adults', Research Perspectives in Music Education, 10:1, pp. 22-27.

SAPA (2013), 'Tshwane has largest ratio of whites in SA', http://www.iol.co.za/pretorianews/tshwane-has-largest-ratio-of-whites-in-sa-1.1457957\#.VXUd5evtU8E. Accessed 14 September 2016

Schippers, Huib (2010), Facing the Music: Shaping Music from a Global Perspective, New York: Oxford University Press.

Silverstein, Merril and Parker, Marti G. (2002), 'Leisure activities and the quality of life among the oldest old in Sweden', Research on Aging, 24:5, pp. 528-48. 
Skingley, Anne, Martin, Anne and Clift, Stephen (2015), 'The contribution of community singing groups to the well-being of older people: Participant perspectives from the United Kingdom', Journal of Applied Gerontology, 35:12, pp. 1302-24.

Smith, Jonathan A. (2005), 'Jonathan A. Smith', http://www.psyc.bbk.ac.uk/people/academic/smith/smith_j/js.html. Accessed 17 April 2015

(2011), 'Evaluating the contribution of interpretative phenomenological analysis', Health Psychology Review, 5:1, pp. 9-27.

Smith, Jonathan A. and Osborn, Mike (2003), 'Interpretive phenomenological analysis', in J. A. Smith (ed.), Qualitative Psychology: A Practical Guide to Research Methods, London: Sage, pp. 51-80.

Smith, Jonathan A., Flowers, Paul and Larkin, Michael (2009), Interpretative Phenomenological Analysis: Theory, Method and Research, London: Sage.

Southcott, Jane and Joseph, Dawn (2013), 'Community, commitment, and the Ten Commandments: Singing in the Coro Furlan', International Journal of Community Music, 6:1, pp. 79-92. 
Specker, Sharonne K. (2014), 'Communities of song: Collective musical participation and group singing experiences in Victoria, BC', The Arbutus Review, 5:1, pp. 6290.

Tarr, Bronwyn, Launay, Jacques and Dunbar, Robin I. M. (2014), 'Music and social bonding: Self-other merging and neurohormonal mechanisms', Frontiers in Psychology, 5, pp. 1-10, http://rsos.royalsocietypublishing.org/content/royopensci/2/10/150221.full.pdf. Accessed 7 July 2016

Tsugawa, Samuel (2009), 'Senior adult music learning, motivation, and meaning construction in two New Horizons ensembles', Doctoral dissertation, Arizona State University, Tempe, Arizona.

Veblen, Kari K. (2013), 'The tapestry: Introducing community music', in K. K. Veblen, S. J. Messenger, M. Silverman and D. J. Elliott (eds), Community Music Today, Plymouth, UK: Roman \& Littlefield Education, pp. 1-12.

Veselinović-Hofman, Mirjana (2009), 'On rethinking the relationship between spirituality and music', New Sounds, 34:2, pp. 115-19.

Weinberg, Melissa and Joseph, Dawn (2017), 'If you're happy and you know it: Music engagement and subjective wellbeing', Psychology of Music, 45:2, pp. 257-67. 
Westermeyer, Paul (2013), 'Music and spirituality: Reflections from a western Christian perspective', Religions, 4:4, pp. 567-83.

Wlodkowski, Raymond J. and Ginsberg, Margery B. (2017), Enhancing Adult Motivation to Learn: A Comprehensive Guide for Teaching all Adults, San Francisco, CA: Jossey-Bass.

White, Mary T. (2016), 'Musical activity across the lifespan as it contributes to quality of life', International Journal of Community Music, 9:2, pp. 157-70.

Yardley, Lucy (2017), 'Demonstrating validity in qualitative psychology', The Journal of Positive Psychology, 12:3, pp. 295-96.

Yin, Robert K. (2003), Case Study Research: Design and Methods, 3rd ed., Thousand Oaks, CA: Sage.

Zanini, Claudia and Leao, Elaine (2006), 'Therapeutic choir: A music therapist looks at the new millennium elderly', Voices, 6:2, http://www.voices.no/mainissues/mi40006000211.html. Accessed 5 August 2016

\section{Contributor details}

Dawn Joseph is an associate professor at Deakin University (Australia). She publishes 
and reviews in national and international journals in music education, teacher education, African music, cultural diversity, multiculturalism and ageing and well-being.

Roy Page-Shipp is a physicist and retired Science Research Manager who has taught parttime at the Gordon Institute of Business Science, University of Pretoria, for over fifteen years. A lifelong singer, he has developed interests in various aspects of Music and Music Education.

Caroline van Niekerk is Emeritus professor of music education at the University of Pretoria, South Africa. During her tenure of approximately twenty years she successfully supervised over 100 masters and doctoral students

Contact:

Dawn Joseph, Deakin University, Faculty of Arts and Education, 221 Burwood Highway, Burwood, 3125, Victoria, Australia.

E-mail: djoseph@deakin.edu.au

Roy Page-Shipp, Gordon Institute of Business Science, University of Pretoria, P. O. Box 787602, Sandton, 2146, South Africa.

E-mail: roy@pageshipp.co.za

Caroline van Niekerk, University of Johannesburg, Faculty of Education, P.O. Box 524, Auckland Park, Johannesburg, 2006, South Africa.

E-mail: caroline@mweb.co.za 